\title{
Performance of pre-commercial release formulations of spinosad against five stored-product insect species on four stored commodities
}

\author{
Bhadriraju Subramanyam • Michelle Hartzer · \\ Dhana Raj Boina
}

Received: 16 May 2011/Accepted: 28 September 2011/Published online: 15 October 2011

(c) The Author(s) 2011. This article is published with open access at Springerlink.com

\begin{abstract}
Two liquid and one dry pre-commercial release spinosad formulations were evaluated at the labeled rate of $1 \mathrm{ppm}$ against five stored-grain insect species on wheat, short-grain rice, long-grain rice, and maize. Except on maize, efficacy of spinosad was compared with a currently registered grain protectant, chlorpyrifos-methyl (3 ppm) plus deltamethrin $(0.5 \mathrm{ppm})$. The 7- and 14-day mortalities of the lesser grain borer, Rhyzopertha dominica, were 99.0-100.0\% on spinosad and chlorpyrifos-methyl plus deltamethrin-treated wheat, short-grain rice, and long-grain rice. Adult progeny of $R$. dominica after 42 days on these commodities decreased by $99.7-100.0 \%$ relative to progeny production on untreated wheat. Mortality and reduction in adult progeny of the rice weevil, Sitophilus oryzae, on the three commodities, and that of the maize weevil, Sitophilus zeamais, on maize and the red flour beetle, Tribolium castaneum, on wheat were $100.0 \%$ only with chlorpyrifos-methyl plus deltamethrin. The liquid spinosad formulations were most effective against the Indianmeal moth, Plodia interpunctella, on maize and wheat. Except for $R$. dominica, the effectiveness of spinosad on the other species varied with the formulation, exposure time, and commodity. Chlorpyrifos-methyl plus deltamethrin was effective against insect species on the commodities tested.
\end{abstract}

Keywords Spinosad formulations - Grain protectants . Stored-grain insects · Efficacy assessment

Communicated by C.G. Athanassiou.

B. Subramanyam $(\bowtie) \cdot$ M. Hartzer $\cdot$ D. R. Boina

Department of Grain Science and Industry, Kansas State

University, Manhattan, KS 66506, USA

e-mail: sbhadrir@k-state.edu

\section{Introduction}

In the United States, stored grain can be treated with malathion, pirimiphos-methyl (Actellic), chlorpyrifos-methyl plus deltamethrin (Storcide II), and several diatomaceous earth formulations to protect against insect infestations for extended periods. Concerns over environmental and human health, along with increased insect resistance to existing insecticides (Subramanyam and Hagstrum 1995) have driven researchers to find novel insecticides that are environmentally benign. Spinosad, a reduced-risk insecticide with low mammalian toxicity, is based on the fermentation products of an actinomycete bacterium, and it is approved for use on many different commodities (Mertz and Yao 1990; Thompson et al. 2000). The United States Environmental Protection Agency approved spinosad for use on stored grain in 2005 (Anonymous 2005), and global launch of spinosad as a grain protectant may be expected in late 2011 or early 2012 pending acceptance of international tolerances by Japan and Australia.

Spinosad is toxic by ingestion and contact, and has a unique mode of action on the insect nervous system at the nicotinic acetylcholine and $\gamma$-aminobutyric acid (GABA) receptor sites (Bret et al. 1997; Salgado 1998). A large volume of scientific data has been gathered from laboratory and field trials with formulations labeled for field crops have shown spinosad to be effective against many storedgrain insect pests (Fang et al. 2002; Toews et al. 2003; Chintzoglou et al. 2008a) on several different commodities (Chintzoglou et al. 2008a; Getchell and Subramanyam 2008; Athanassiou et al. 2010; Kavallieratos et al. 2010; Vayias et al. 2010a).

However, for use as a grain protectant, the spinosad formulations used for field crops may not be suitable because of differences in percentage active ingredient and inclusion of 
specific inert ingredients. The formulator of spinosad (Bayer CropScience, Research Triangle Park, NC, USA) sent two liquid pre-commercial formulations of spinosad and a dry formulation of spinosad for efficacy assessment against several stored-grain insects on four commodities. Such an evaluation is necessary to assure the performance of the formulation before global launch of commercial formulations into the market. Furthermore, information is unavailable on the efficacy of spinosad formulations compared to currently registered grain protectant, chlorpyrifos-methyl plus deltamethrin, on three main grain commodities, wheat, long-grain rice, and short-grain rice. Therefore, a series of laboratory tests was conducted to evaluate three pre-commercial release formulations of spinosad, primarily developed for use on stored grains, against economically important insect species on wheat, maize, long-grain rice, and short-grain rice. We hypothesize that the pre-commercial formulations intended solely for use on stored grains are equal or greater in effectiveness than spinosad formulations labeled for field crops that were previously evaluated against stored-grain insects.

\section{Materials and methods}

\section{Insecticides}

Two liquid and one dry formulations of spinosad and chlorpyrifos-methyl plus deltamethrin were supplied by Bayer CropScience. One of the liquid spinosad formulations (Contain I or Liquid spinosad I) had a purity of $86.6 \mathrm{mg} \mathrm{AI}$ $\mathrm{ml}^{-1}$ while the other (Contain II or Liquid spinosad II) had $232.0 \mathrm{mg} \mathrm{AI} \mathrm{ml}^{-1}$ purity. The dry spinosad formulation was $0.5 \%$ pure ( $5 \mathrm{mg}$ AI spinosad $\mathrm{g}^{-1}$ of formulation). The purity of chlorpyrifos-methyl plus deltamethrin (C-methyl + D) formulation was $216.0 \mathrm{mg} \mathrm{AI} \mathrm{ml}{ }^{-1}$ of chlorpyrifos-methyl

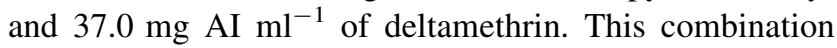
product is registered in the United States for use on wheat and paddy rice but not on maize.

\section{Insect cultures}

The insect species used in bioassays included the lesser grain borer, Rhyzopertha dominica (F.) (Coleoptera: Bostrichidae); rice weevil, Sitophilius oryzae (L.) (Coleoptera: Curculionidae); maize weevil, Sitophilius zeamais (Motschulsky) (Coleoptera: Curculionidae); red flour beetle, Tribolium castaneum (Herbst) (Coleoptera: Tenebrionidae); and Indianmeal moth, Plodia interpunctella (Hübner) (Lepidoptera: Pyralidae). Cultures of $R$. dominica and $S$. oryzae were reared on clean, organic hard red winter wheat (Heartland Mills, Marienthal, KS, USA), and $S$. zeamais was reared on clean, organic maize obtained from Heartland Mills. Cultures of $T$. castaneum were reared on white wheat flour plus brewer's yeast diet $(5 \%$ by wt), and cultures of $P$. interpunctella were reared on a poultry mash diet (Subramanyam and Cutkomp 1987). Briefly, the moth diet consisted of poultry mash from a local feed mill $(1,000 \mathrm{~g})$, glycerol $(150 \mathrm{ml})$, honey $(150 \mathrm{ml})$, and distilled water $(75 \mathrm{ml})$. All insect colonies were reared at, and all bioassays were conducted at, $28^{\circ} \mathrm{C}$, $65 \%$ relative humidity $(\mathrm{RH})$, and 14:10 h L/D photoperiod in the Department of Grain Science and Industry, Kansas State University, Manhattan, KS, USA.

\section{Grain treatment and insect exposure}

The short-grain rice and long-grain rice were procured from Lundberg Family Farms (Richvale, CA, USA). The organic hard red winter wheat and organic maize were obtained from Heartland Mills. The liquid spinosad formulations and chlorpyrifos-methyl plus deltamethrin formulation were diluted in distilled water. Each commodity (100 g) in separate 0.45 -L glass jars was treated by adding $100 \mu \mathrm{l}$ of the aqueous solution of spinosad $\left(1 \mathrm{mg} \mathrm{AI} \mathrm{ml}^{-1}\right)$ to obtain a spinosad rate of $1 \mathrm{ppm}$ or a chlorpyrifos-methyl rate of $3 \mathrm{ppm}$ and deltamethrin rate of $0.5 \mathrm{ppm}$. Each commodity $(100 \mathrm{~g})$, in separate $0.45-\mathrm{L}$ glass jars, was admixed with $0.02 \mathrm{~g}$ of the dry formulation to obtain a spinosad rate of $1 \mathrm{ppm}$. There were two separate control treatments, one for the liquid formulation (wet control) and one for the dry formulation (dry control). Jars with $100 \mathrm{~g}$ of each commodity receiving $100 \mu$ of distilled water served as the wet control. The dry control consisted of jars with $100 \mathrm{~g}$ of each untreated commodity. All jars, except for dry controls, were shaken by hand for $1 \mathrm{~min}$ to facilitate coverage of insecticide on the kernels.

Different insect species were introduced into jars holding different commodities. The jars with wheat were infested with $50 \mathrm{R}$. dominica, $50 \mathrm{~S}$. oryzae, or $50 \mathrm{~T}$. castaneum adults, whereas jars with short- and long-grain rices were infested separately only with the first two species. Jars with maize were infested with $50 \mathrm{~S}$. zeamais or $50 \mathrm{~T}$. castaneum adults. Eggs (50) of $P$. interpunctella, laid with $24 \mathrm{~h}$ of moth collection, were added to jars containing either wheat or maize. Eggs of $P$. interpunctella used in experiments were collected by the procedure described by Bell (1976). Briefly, this method involved collecting newly emerged adults from cultures jars by anesthetizing them with carbon dioxide and transferring adults to clean $0.95-\mathrm{L}$ glass jars. The jars with adults were placed over mesh to collect the eggs in clean glass Petri dishes (90-mm diameter) placed below the mesh.

After egg or adult introduction, jars were closed with metal lids fitted with wire-mesh screens and filter papers and held at $28^{\circ} \mathrm{C}, 65 \% \mathrm{RH}$, and 14:10 h L/D photoperiod. 
Separate sets of jars holding untreated and insecticidetreated commodities infested with beetles were observed on days 7 and 14 after infestation to count number of live and dead insects, after which the jar contents were discarded. An independent set of jars was observed at 42 days to count number of adult progeny produced. The actual adult progeny produced was based on total number of adults found minus the original number (50) introduced to infest the samples. A set of jars with wheat and maize infested with $P$. interpunctella was observed 21 days postinfestation to count number of live larvae present; another set of jars was observed after 42 days to count number of moths that emerged from the introduced eggs. Each commodity-species-observation time combination was replicated five times.

\section{Data analyses}

Data on the number of dead beetles out of the total exposed on untreated and insecticide-treated commodities after 7 and 14 days were used to calculate percent mortality. Mortality data on insecticide-treated commodities were corrected for mortality on untreated (control) commodities (Abbott 1925). The wet control was used to correct mortality data from liquid insecticide treatments, and the dry control was used to correct mortality data from dry insecticide treatments. Corrected mortality data by commodity and species at 7 and 14 days, among the treatments, were transformed to angular values (Zar 1984) to normalize heteroscedastic treatment variances and subjected to oneway analysis of variance (ANOVA) to determine significant differences (SAS Institute 2005). If ANOVA was significant $(P<0.05)$, treatment means were separated using Ryan-Einot-Gabriel-Welsch (REGWQ) test (SAS Institute 2005). Adult beetle progeny production data in control and insecticide treatments by species and commodity were analyzed by one-way ANOVA and REGWQ test after transformation of data $(x)$ to $\log _{10}(x)$ or $\log _{10}$ $(x+1)$ scale. Data on the number of live larvae of $P$. interpunctella among treatments after 21 days and number of moths that emerged among treatments after 42 days were transformed to $\log _{10}(x)$ or $\log _{10}(x+1)$ scale and subjected to one-way ANOVA, followed by least squares means (LSMEANS) test for determining significant differences $(P=0.05)$ among treatments.

\section{Results}

Natural mortality of beetles on commodities

The mortality of insects on commodities treated with distilled water (wet control) was generally below $4 \%$ except in three cases (Table 1). The mortality of $R$. dominica on day 7 on wheat and long-grain rice was $14-16 \%$ and that of $S$. oryzae on day 14 on long-grain rice was $17 \%$. On commodities that were untreated (dry control), only the mortality of $S$. oryzae on long-grain rice on day 14 was about $17.6 \%$, while that of the other species was less than $6.6 \%$ (Table 2). The high level of mortality observed for certain species is not uncommon (Getchell and Subramanyam 2008) and could be due to using mixed ages of insects in bioassays.

Responses of beetles exposed to insecticide-treated commodities

Table 3 shows the corrected mortality of the four insect species on four commodities. Chlorpyrifos-methyl plus deltamethrin provided complete control of $R$. dominica, $S$. oryzae, and T. castaneum within 7 days of exposure to the treated commodities. All three spinosad formulations were as effective as chlorpyrifos-methyl plus deltamethrin against $R$. dominica on wheat, short-grain rice, and longgrain rice, because $100.0 \%$ mortality was obtained within 7 days after infestation. The mortality of $S$. oryzae on wheat, short-grain rice, and long-grain rice ( $d f$ by commodity $=7,32)$, S. zeamais on maize $(d f=5,24)$, and $T$. castaneum on wheat $(d f=7,32)$ and maize $(d f=5,24)$ was significantly different among the insecticide treatments $(F$, range among commodities $=7.53-178.59$; $P<0.0001)$.

The two liquid and one dry spinosad formulations produced $\leq 16 \%$ mortality of $T$. castaneum adults on wheat and maize even after 14 days of continuous exposure (Table 3). Mortality of $S$. oryzae exposed to spinosadtreated commodities varied by commodity, exposure time, and spinosad formulation. The mortality of $S$. oryzae on wheat exposed to spinosad was significantly higher $(P<0.05)$ at 14 days than at 7 days, and the 14-day mortality was comparable to that observed on chlorpyrifosmethyl plus deltamethrin treatment (Table 3). On shortgrain rice, mortality with the two liquid spinosad formulations was comparable to that of chlorpyrifos-methyl plus deltamethrin. The dry spinosad formulation was significantly less effective against $S$. oryzae than all other treatments, and none of the formulations produced $100.0 \%$ mortality. In contrast, the dry spinosad and spinosad liquid I formulations produced significantly higher $S$. oryzae mortality on long-grain rice compared with spinosad liquid II formulation. The former two formulations were as effective as chlorpyrifos-methyl plus deltamethrin (Table 3). On maize, the two liquid spinosad formulations produced near complete-to-complete mortality of $S$. zeamais (99.6$100.0 \%)$, which was significantly greater $(P<0.05)$ than that observed in dry spinosad treatments. 
Table 1 Mortality of adults (mean $\pm \mathrm{SE}$ ) of four insect species exposed for 7 and 14 days to commodities treated with $100 \mu \mathrm{l}$ of distilled water (wet control)

Each mean is based on $n=5$

a $n=4,1$ missing value

b $n=4,1$ missing value

c $n=4,1$ missing value

${ }^{\mathrm{d}} n=3,2$ missing values

Table 2 Mortality of adults (mean \pm SE) of four insect species exposed for 7 and 14 days to untreated commodities (dry control)

Each mean is based on $n=5$

${ }^{\text {a }} n=4,1$ missing value

${ }^{\mathrm{b}} n=2,3$ missing values

\begin{tabular}{lccccc}
\hline Commodity & $\begin{array}{l}\text { Exposure } \\
\text { time (days) }\end{array}$ & R. dominica & S. oryzae & S. zeamais & T. castaneum \\
\hline Wheat & 7 & $16.5 \pm 4.3$ & $1.2 \pm 0.5$ & \\
& 14 & $3.0 \pm 1.3^{\mathrm{a}}$ & $3.7 \pm 0.8$ & & $2.2 \pm 2.1$ \\
Short-grain rice & 7 & $3.3 \pm 1.6$ & $0.0 \pm 0.0$ & & \\
& 14 & $3.0 \pm 1.7^{\mathrm{b}}$ & $1.2 \pm 0.5$ & & \\
Long-grain rice & 7 & $14.3 \pm 4.4^{\mathrm{c}}$ & $1.6 \pm 0.4$ & & \\
& 14 & $3.3 \pm 1.8^{\mathrm{d}}$ & $17.1 \pm 4.8$ & & $0.0 \pm 0.0$ \\
Maize & 7 & & & $2.8 \pm 1.4$ & $0.8 \pm 0.8$ \\
& 14 & & & & \\
\hline
\end{tabular}

\begin{tabular}{lclccc}
\hline Commodity & $\begin{array}{l}\text { Exposure } \\
\text { time (days) }\end{array}$ & $R$. dominica & S. oryzae & S. zeamais & T. castaneum \\
\hline Wheat & 7 & $0.0 \pm 0.0^{\mathrm{a}}$ & $1.3 \pm 0.8$ & & $0.8 \pm 0.8$ \\
& 14 & $2.8 \pm 1.5$ & $6.4 \pm 1.2$ & & \\
Short-grain rice & 7 & $0.8 \pm 0.8$ & $1.7 \pm 0.8$ & & \\
& 14 & $6.5 \pm 2.0^{\mathrm{b}}$ & $3.8 \pm 0.5$ & & \\
Long-grain rice & 7 & $5.1 \pm 1.6$ & $1.7 \pm 1.7$ & & \\
& 14 & $3.6 \pm 1.3$ & $17.6 \pm 3.3$ & & $0.0 \pm 0.0$ \\
Maize & 7 & & & $4.6 \pm 1.2$ & $0.0 \pm 0.0$ \\
& 14 & & & 4.7 & \\
\hline
\end{tabular}

Adult progeny production on commodities

Progeny production of $R$. dominica on untreated and insecticide-treated wheat, short-grain rice, and long-grain rice ( $d f$ by commodity $=5,24$ ) was significantly different $(F$, range $=16.92-97.80 ; P<0.0001)$. Progeny production of $S$. oryzae on wheat $(d f=5,23)$, short-grain rice $(d f=5,24)$, long-grain rice $(d f=5,24)$, and that of $T$. castaneum on wheat $(d f=5,24)$ was different among the treatments $(F$, range among commodities and species $=13.87-397.20 ; P<0.0001)$. Similar differences in progeny production were observed for $S$. zeamais and $T$. castaneum on maize $(F$, range between species $=$ 13.27-13.83; $d f=4,20 ; P<0.0001)$.

Progeny production of all insect species was consistently higher in untreated commodities (dry and wet controls) compared with production on insecticide-treated commodities (Table 4). The progeny production was minimal $(<3)$ for $R$. dominica, S. oryzae, and T. castaneum in chlorpyrifos-methyl plus deltamethrin-treated wheat, short-grain rice, and long-grain rice. In general, all spinosad formulations effectively suppressed progeny production of the four insect species on wheat, short-grain rice, and long-grain rice. On these three commodities, the two liquid formulations performed better against $R$. dominica than the dry spinosad formulation. The dry formulation performed well against $S$. zeamais and $T$. castaneum on maize, but not against $T$. castaneum on wheat. The two liquid spinosad formulations were only partially effective in suppressing progeny of $S$. oryzae on wheat, short-grain rice, and long-grain rice. About 16-278 adults were produced in liquid spinosad treatments across the three commodities compared to 88-998 adults on untreated commodities. Less than 1 adult of $S$. oryzae was found in wheat and long-grain rice treated with the dry spinosad formulation, but close to 59 adults were produced on shortgrain rice treated with the same formulation. We cannot explain these anomalous results with dry spinosad on wheat and long-grain rice.

Responses of $P$. interpunctella on untreated and insecticide-treated commodities

Fewer (0-0.4) P. interpunctella larvae were observed on insecticide-treated commodities at 21 days compared to the control treatment (9-24 larvae) on both wheat $(F=9.14$; $d f=5,24 ; P<0.0001)$ and maize $(F=68.29 ; d f=4$, $20 ; P<0.0001)$ (Table 5). None of the larvae survived on wheat treated with the two liquid spinosad formulations and chlorpyrifos-methyl plus deltamethrin, while the survival of this species on insecticide-treated maize was negligible.

On spinosad-treated maize, no $P$. interpunctella adults were found after 42 days (Table 5). Similarly, no 
Table 3 Corrected mortality of adults (mean \pm SE) of four insect species exposed for 7 and 14 days to $1 \mathrm{mg}^{\mathrm{AI}} \mathrm{kg}^{-1} \mathrm{dry}_{\mathrm{and}}$ liquid spinosad formulations and chlorpyrifos-methyl (C-methyl) plus deltamethrin (D) applied to four commodities

\begin{tabular}{|c|c|c|c|c|c|c|}
\hline Commodity & Formulation & Exposure time (days) & $R$. dominica ${ }^{\mathrm{a}}$ & S. oryzae & S. zeamais & T. castaneum \\
\hline \multirow[t]{8}{*}{ Wheat } & \multirow[t]{2}{*}{ Dry spinosad } & 7 & $100.0 \pm 0.0$ & $81.0 \pm 9.0 \mathrm{~b}$ & & $4.0 \pm 2.4 \mathrm{~b}$ \\
\hline & & 14 & $100.0 \pm 0.0$ & $98.7 \pm 0.5 \mathrm{a}$ & & $3.7 \pm 1.4 \mathrm{~b}$ \\
\hline & \multirow[t]{2}{*}{ Liquid spinosad I } & 7 & $100.0 \pm 0.0$ & $90.7 \pm 1.9 \mathrm{~b}$ & & $0.4 \pm 2.7 b$ \\
\hline & & 14 & $100.0 \pm 0.0$ & $99.6 \pm 0.4 \mathrm{a}$ & & $6.6 \pm 0.8 b$ \\
\hline & \multirow[t]{2}{*}{ Liquid spinosad II } & 7 & $100.0 \pm 0.0$ & $78.1 \pm 3.5 b$ & & $0.4 \pm 2.3 b$ \\
\hline & & 14 & $100.0 \pm 0.0$ & $98.8 \pm 0.8 \mathrm{a}$ & & $12.3 \pm 5.3 b$ \\
\hline & \multirow[t]{2}{*}{ C-methyl + D } & 7 & $100.0 \pm 0.0$ & $100.0 \pm 0.0 \mathrm{a}$ & & $100.0 \pm 0.0 \mathrm{a}$ \\
\hline & & 14 & $100.0 \pm 0.0$ & $100.0 \pm 0.0 \mathrm{a}$ & & $100.0 \pm 0.0 \mathrm{a}$ \\
\hline \multirow[t]{8}{*}{ Short-grain rice } & \multirow[t]{2}{*}{ Dry spinosad } & 7 & $100.0 \pm 0.0$ & $36.0 \pm 5.0 \mathrm{~d}$ & & \\
\hline & & 14 & $100.0 \pm 0.0$ & $62.2 \pm 7.9 \mathrm{c}$ & & \\
\hline & \multirow[t]{2}{*}{ Liquid spinosad I } & 7 & $100.0 \pm 0.0$ & $97.2 \pm 1.5 \mathrm{ab}$ & & \\
\hline & & 14 & $100.0 \pm 0.0$ & $89.7 \pm 4.0 \mathrm{~b}$ & & \\
\hline & \multirow[t]{2}{*}{ Liquid spinosad II } & 7 & $100.0 \pm 0.0$ & $98.0 \pm 0.6 \mathrm{ab}$ & & \\
\hline & & 14 & $100.0 \pm 0.0$ & $96.8 \pm 1.2 \mathrm{ab}$ & & \\
\hline & \multirow[t]{2}{*}{ C-methyl + D } & 7 & $100.0 \pm 0.0$ & $100.0 \pm 0.0 \mathrm{a}$ & & \\
\hline & & 14 & $100.0 \pm 0.0$ & $100.0 \pm 0.0 \mathrm{a}$ & & \\
\hline \multirow[t]{8}{*}{ Long-grain rice } & \multirow[t]{2}{*}{ Dry spinosad } & 7 & $100.0 \pm 0.0$ & $98.4 \pm 0.8 \mathrm{a}$ & & \\
\hline & & 14 & $100.0 \pm 0.0$ & $98.6 \pm 1.0 \mathrm{a}$ & & \\
\hline & \multirow[t]{2}{*}{ Liquid spinosad I } & 7 & $100.0 \pm 0.0$ & $95.9 \pm 2.5 \mathrm{a}$ & & \\
\hline & & 14 & $100.0 \pm 0.0$ & $100.0 \pm 0.0 \mathrm{a}$ & & \\
\hline & \multirow[t]{2}{*}{ Liquid spinosad II } & 7 & $100.0 \pm 0.0$ & $87.8 \pm 2.1 \mathrm{~b}$ & & \\
\hline & & 14 & $98.8 \pm 1.2$ & $87.3 \pm 3.8 \mathrm{~b}$ & & \\
\hline & \multirow[t]{2}{*}{ C-methyl + D } & 7 & $100.0 \pm 0.0$ & $100.0 \pm 0.0 \mathrm{a}$ & & \\
\hline & & 14 & $100.0 \pm 0.0$ & $100.0 \pm 0.0 \mathrm{a}$ & & \\
\hline \multirow[t]{6}{*}{ Maize } & \multirow[t]{2}{*}{ Dry spinosad } & 7 & & & $43.5 \pm 10.0 \mathrm{c}$ & $2.8 \pm 0.8 \mathrm{bc}$ \\
\hline & & 14 & & & $87.1 \pm 5.5 b$ & $16.0 \pm 2.8 \mathrm{a}$ \\
\hline & \multirow[t]{2}{*}{ Liquid spinosad I } & 7 & & & $99.6 \pm 0.4 \mathrm{a}$ & $2.8 \pm 1.4 \mathrm{bc}$ \\
\hline & & 14 & & & $100.0 \pm 0.0 \mathrm{a}$ & $8.1 \pm 1.9 \mathrm{ab}$ \\
\hline & \multirow[t]{2}{*}{ Liquid spinsad II } & 7 & & & $100.0 \pm 0.0 \mathrm{a}$ & $1.6 \pm 1.0 \mathrm{c}$ \\
\hline & & 14 & & & $99.6 \pm 0.4 \mathrm{a}$ & $7.7 \pm 2.2 \mathrm{ab}$ \\
\hline
\end{tabular}

Each mean is based on $n=5$

For each species and commodity, means followed by different letters are significantly different $(P<0.05$, REGWQ test $)$

${ }^{\text {a }}$ For $R$. dominica on long-grain rice, means among treatments are not different from one another $(F=1.00 ; d f=7,32 ; P=0.45 ;$ one-way ANOVA)

$P$. interpunctella adults were observed on liquid spinosadtreated wheat; however, the number of adults that emerged on dry spinosad-treated wheat was similar to those on untreated wheat.

\section{Discussion}

Spinosad's efficacy against stored-grain insects and their progeny production depends on several factors such as formulation, commodity, temperature, application rate, and insect species (Huang et al. 2004; Huang and Subramanyam 2007; Athanassiou et al. 2008a, b, 2009, 2010, 2011;
Vayias et al. 2010b). The toxicity of spinosad varies among different populations and different life stages of an insect species (Toews and Subramanyam 2003; Huang et al. 2004; Athanassiou et al. 2008c). Furthermore, the susceptibility of an insect species to spinosad varies among different classes or varieties of a commodity (Fang et al. 2002). Therefore, in this study, we evaluated the efficacy of three pre-commercial release spinosad formulations against five stored-grain insect species. Additionally, for the first time, on three commodities, the efficacy of spinosad formulations was compared to currently registered grain protectant, chlorpyrifos-methyl plus deltamethrin. In this study, spinosad formulations were not compared with 
Table 4 Adult progeny production (mean \pm SE) after 42 days of four insect species in untreated and insecticide-treated commodities

\begin{tabular}{|c|c|c|c|c|c|}
\hline Commodity & Treatment & R. dominica & S. oryzae & S. zeamais & T. castaneum \\
\hline \multirow[t]{6}{*}{ Wheat } & Dry control & $71.0 \pm 38.3 b$ & $977.8 \pm 72.2 \mathrm{a}$ & & $58.3 \pm 8.7 \mathrm{ab}$ \\
\hline & Wet control & $159.6 \pm 28.4 \mathrm{a}$ & $998.2 \pm 35.0 \mathrm{a}$ & & $100.4 \pm 18.4 \mathrm{a}$ \\
\hline & Dry spinosad & $0.0 \pm 0.0 \mathrm{c}$ & $0.4 \pm 0.4 \mathrm{c}$ & & $19.0 \pm 15.8 b c$ \\
\hline & Liquid spinosad I & $0.0 \pm 0.0 \mathrm{c}$ & $230.6 \pm 23.9 b$ & & $1.2 \pm 1.0 \mathrm{c}$ \\
\hline & Liquid spinosad II & $0.0 \pm 0.0 \mathrm{c}$ & $277.8 \pm 30.4 b$ & & $0.6 \pm 0.4 \mathrm{c}$ \\
\hline & C-methyl + D & $0.2 \pm 0.2 \mathrm{c}$ & $0.6 \pm 0.4 \mathrm{c}$ & & $0.0 \pm 0.0 \mathrm{c}$ \\
\hline \multirow[t]{6}{*}{ Short-grain rice } & Dry control & $41.0 \pm 10.3 \mathrm{a}$ & $123.0 \pm 4.4 \mathrm{a}$ & & \\
\hline & Wet control & $82.4 \pm 10.7 \mathrm{a}$ & $88.0 \pm 2.7 \mathrm{ab}$ & & \\
\hline & Dry spinosad & $2.6 \pm 1.7 \mathrm{~b}$ & $58.6 \pm 10.8 \mathrm{abc}$ & & \\
\hline & Liquid spinosad I & $0.0 \pm 0.0 \mathrm{~b}$ & $26.2 \pm 6.9 c$ & & \\
\hline & Liquid spinosad II & $0.0 \pm 0.0 \mathrm{~b}$ & $30.6 \pm 8.8 b c$ & & \\
\hline & C-methyl + D & $2.6 \pm 1.7 b$ & $0.0 \pm 0.0 \mathrm{~d}$ & & \\
\hline \multirow[t]{6}{*}{ Long-grain rice } & Dry control & $12.0 \pm 2.6 \mathrm{a}$ & $91.0 \pm 8.0 \mathrm{a}$ & & \\
\hline & Wet control & $18.2 \pm 6.6 \mathrm{a}$ & $132.2 \pm 11.3 \mathrm{a}$ & & \\
\hline & Dry spinosad & $0.8 \pm 0.4 b$ & $0.8 \pm 0.6 b$ & & \\
\hline & Liquid spinosad I & $0.0 \pm 0.0 \mathrm{~b}$ & $16.0 \pm 14.8 b$ & & \\
\hline & Liquid spinosad II & $0.2 \pm 0.2 b$ & $43.2 \pm 3.2 \mathrm{a}$ & & \\
\hline & C-methyl + D & $0.0 \pm 0.0 \mathrm{~b}$ & $0.0 \pm 0.0 \mathrm{~b}$ & & \\
\hline \multirow[t]{5}{*}{ Maize } & Dry control & & & $68.4 \pm 19.0 \mathrm{a}$ & $2.2 \pm 1.3 b$ \\
\hline & Wet control & & & $34.0 \pm 1.9 \mathrm{a}$ & $7.6 \pm 2.4 \mathrm{a}$ \\
\hline & Dry spinosad & & & $7.4 \pm 5.0 \mathrm{~b}$ & $0.0 \pm 0.0 \mathrm{~b}$ \\
\hline & Liquid spinosad I & & & $0.0 \pm 0.0 \mathrm{~b}$ & $0.0 \pm 0.0 \mathrm{~b}$ \\
\hline & Liquid spinosad II & & & $0.0 \pm 0.0 \mathrm{~b}$ & $0.2 \pm 0.2 b$ \\
\hline
\end{tabular}

Each mean is based on $n=5$

For each species and commodity, means followed by different letters are significantly different $(P<0.05$; REGWQ test $)$

C-methyl + D, Chlorpyrifos-methyl + deltamethrin

pirmiphos-methyl, which is currently registered in the United States for use on stored maize, because spinosad was shown to be more effective than 4 ppm pirimiphosmethyl against $S$. zeamais (Szabela 2005). Spinosad was highly effective against $R$. dominica adults because all adults were killed within 7 days and progeny production was completely suppressed. This is expected because previous studies have shown increased susceptibility of $R$. dominica to liquid or dry spinosad at low rates (Huang and Subramanyam 2007; Getchell and Subramanyam 2008; Athanassiou et al. 2008a, b, 2009, 2010, 2011). All spinosad formulations were slightly less effective against $S$. oryzae, and the dry spinosad formulation provided the least control of $S$. oryzae adults on short-grain rice, but it was still more effective than the control treatments. Dry formulation exhibited the least activity on $S$. oryzae adults compared to liquid formulations on short-grain rice, but it did not result in higher progeny production than that of liquid formulations. Similarly, the activity of liquid formulations against adults was comparable to the dry formulation on wheat and long-grain rice but resulted in higher progeny production than that of the dry formulation.
The complete and near complete control of $R$. dominica and $S$. oryzae adults, respectively, achieved with all spinosad formulations were not reflected in progeny suppression between these species. The complete suppression of adult progeny production in the case of $R$. dominica is due to the complete control of neonates as this species lays eggs outside the kernels and the larvae have to find suitable kernels to enter and continue their development (Arbogast 1991). In the search of finding a suitable entry site on kernels, the first instars succumb to spinosad. However, female $S$. oryzae adults lay eggs directly within the kernels after making a shallow cavity. Since $S$. oryzae adults are not as highly susceptible as $R$. dominica to spinosad (Fang et al. 2002; Toews and Subramanyam 2003), the surviving adults have a chance to mate and lay eggs within kernels before they succumb to spinosad. The differences in adult susceptibility to spinosad and egg-laying behaviors, among other things, explain why spinosad is more effective against $R$. dominica than $S$. oryzae. In spinosad-treated grain, progeny production of $R$. dominica and $S$. oryzae is directly related to the speed of death of adults (Athanassiou et al. 2010), because surviving insects can still mate and lay 
Table 5 Mean \pm SE number of live larvae of $P$. interpunctella at 21 days and number of adults that emerged from eggs at 42 days on untreated and insecticide-treated commodities

\begin{tabular}{|c|c|c|c|c|}
\hline $\begin{array}{l}\text { Observation } \\
\text { time (days) }\end{array}$ & Commodity & Treatment & Number of larvae & $\begin{array}{l}\text { Number of } \\
\text { adults }\end{array}$ \\
\hline \multirow[t]{11}{*}{21} & \multirow[t]{6}{*}{ Wheat } & Dry control & $23.8 \pm 8.0 \mathrm{a}$ & \\
\hline & & Wet control & $9.4 \pm 3.5 \mathrm{a}$ & \\
\hline & & Dry spinosad & $1.0 \pm 0.6 \mathrm{~b}$ & \\
\hline & & Liquid spinosad I & $0.0 \pm 0.0 \mathrm{~b}$ & \\
\hline & & Liquid spinosad II & $0.0 \pm 0.0 \mathrm{~b}$ & \\
\hline & & C-methyl + D & $0.0 \pm 0.0 \mathrm{~b}$ & \\
\hline & \multirow[t]{5}{*}{ Maize } & Dry control & $11.0 \pm 2.1 \mathrm{a}$ & \\
\hline & & Wet control & $11.4 \pm 1.7 \mathrm{a}$ & \\
\hline & & Dry spinosad & $0.2 \pm 0.2 b$ & \\
\hline & & Liquid spinosad I & $0.2 \pm 0.2 b$ & \\
\hline & & Liquid spinosad II & $0.4 \pm 0.2 b$ & \\
\hline \multirow[t]{11}{*}{42} & \multirow[t]{6}{*}{ Wheat } & Dry control & & $12.8 \pm 7.4 \mathrm{a}$ \\
\hline & & Wet control & & $6.0 \pm 3.2 \mathrm{a}$ \\
\hline & & Dry spinosad & & $8.2 \pm 3.8 \mathrm{a}$ \\
\hline & & Liquid spinosad I & & $0.0 \pm 0.0 \mathrm{~b}$ \\
\hline & & Liquid spinosad II & & $0.0 \pm 0.0 \mathrm{~b}$ \\
\hline & & C-methyl + D & & $0.0 \pm 0.0 \mathrm{~b}$ \\
\hline & \multirow[t]{5}{*}{ Maize } & Dry control & & $0.6 \pm 0.6 \mathrm{a}$ \\
\hline & & Wet control & & $0.8 \pm 0.8 b$ \\
\hline & & Dry spinosad & & $0.0 \pm 0.0 \mathrm{~b}$ \\
\hline & & Liquid spinosad I & & $0.0 \pm 0.0 \mathrm{~b}$ \\
\hline & & Liquid spinosad II & & $0.0 \pm 0.0 \mathrm{~b}$ \\
\hline
\end{tabular}

Each mean is based on $n=5$

For each species and commodity, means followed by different letters are significantly different $(P<0.05$; LSMEANS test)

C-methyl + D, Chlorpyrifosmethyl + deltamethrin type may play a role in spinosad's efficacy against storedgrain insects (Chintzoglou et al. 2008a; Athanassiou et al. 2008a).

The two liquid formulations were highly effective against adults of $S$. zeamais on maize leading to the complete suppression of progeny production, while moderate to high control of adults achieved with dry formulation did not result in high progeny production. The complete control of $S$. zeamais adults and progeny production obtained with two liquid formulations on maize is in agreement with Huang and Subramanyam (2007), who reported similar results with a commercial liquid formulation of spinosad used on field crops (SpinTor 2SC). The lack of effectiveness of the dry formulation when compared with the liquid formulation has been reported previously (Chintzoglou et al. 2008b) and could be due to poor adherence or retention of the dry formulation on the kernels.

Spinosad was not very effective on $T$. castaneum adults, either on wheat or maize. These results are in agreement with previous studies, where a maximum of $10 \%$ adult mortality of this species at similar rates was reported by Athanassiou et al. (2010) on wheat and maize, and by Toews and Subramanyam (2003) on whole wheat, cracked wheat, and wheat flour. Although one population of a related species, the confused flour beetle, Tribolium confusum (Jacquelin du Val) (Coleoptera: Tenebrionidae), 
showed higher susceptibility to a dry formulation of spinosad on wheat at 0.06 and $0.19 \mathrm{ppm}$, but a majority of populations collected from various locations in Europe were less susceptible to spinosad (Athanassiou et al. 2008c). Furthermore, topical application bioassays conducted on T. castaneum adults using a commercial formulation of spinosad intended for field crops (Tracer 24SC) at $28^{\circ} \mathrm{C}$ and $65 \% \mathrm{RH}$ showed this species to be less susceptible than $R$. dominica and $S$. oryzae to spinosad (Yousefnezhad-Irani and Asghra 2007a, b). Similar findings were reported by Toews and Subramanyam (2003) using residual bioassays in glass Petri dishes. The low adult progeny production on spinosad-treated commodities suggested that spinosad was highly toxic to $T$. castaneum immatures (neonates). This finding is consistent with complete suppression of $T$. castaneum adult emergence observed at similar rates on wheat where the insects were exposed as eggs for 14 days (Flinn et al. 2004; Subramanyam et al. 2007).

Like $R$. dominica, all formulations of spinosad were extremely effective against $P$. interpunctella based on negligible larval survival and adult emergence observed on wheat and maize. These results are consistent with greater susceptibility of $P$. interpunctella eggs and larvae to a commercial spinosad formulation (SpinTor 2SC) reported by Huang et al. (2004).

Spinosad is considered as one of the best alternatives to organophosphate grain protectants that have high mammalian toxicity (Hertlein et al. 2011). Additionally, spinosad is of bacterial origin and possesses low mammalian toxicity (Thompson et al. 2000), and it is stable on commodities without loss of insecticidal efficacy for 12-24 months (Bonjour et al. 2006; Subramanyam et al. 2007). All of these attributes make spinosad an ideal and novel grain protectant. Spinosad was most effective against $R$. dominica, S. zeamais, and P. interpunctella on various commodities. The lack of control against $T$. castaneum adults is less of a concern because spinosad is highly effective against the immature stages thereby preventing population growth of this species. The effectiveness against $S$. oryzae on commodities may be improved by combining spinosad with another approved insecticide at lower rates such as chlorpyrifos-methyl plus deltamethrin, which, in this study, was very effective against the insect species tested on different commodities. Subramanyam et al. (2007) reported that chlorpyrifos-methyl at $3 \mathrm{ppm}$ was ineffective against $R$. dominica but effective against $T$. castaneum in stored wheat. The effectiveness of chlorpyrifos-methyl plus deltamethrin against $R$. dominica can therefore be attributed to deltamethrin in this combination product. This combination product is not registered in the United States for use on maize. On maize, spinosad could be combined with lower rates of pirimiphos-methyl to control Sitophilus spp. (Hertlein et al. 2011). Nevertheless, according to Vayias et al. (2010b), spinosad plus deltamethrin applied to two wheat varieties were not effective against $S$. oryzae. Similarly, spinosad (0.1 or $0.5 \mathrm{ppm})$ combined with an insect growth regulator, methoprene (1 or $5 \mathrm{ppm}$ ), did not result in greater mortality or greater suppression of progeny production against six stored-grain insect species namely, $R$. dominica, $S$. oryzae; the granary weevil, Sitophilus granarius (L.) (Coleoptera: Curculionidae); the rusty grain beetle, Cryptolestes ferrugineus (Stephens) (Coleoptera: Laemophloeidae); the sawtoothed grain beetle, Oryzaephilus surinamensis (L.) (Coleoptera: Silvanidae); and the psocid, Liposcelis bostrychophila (Bodonnel) (Psocoptera: Liposcelididae), than spinosad used alone (Athanassiou et al. 2011). Thus, the concept of combining spinosad with other insecticides needs further evaluation both in terms of efficacy and cost. Overall, the effectiveness of pre-commercial release formulations of spinosad was similar to formulations tested in our laboratory and by other researchers worldwide, despite differences in the active ingredient and proprietary inert ingredients. The liquid formulations tended to be more effective than the dry formulation. The availability of commercial formulations in the near future will add another valuable tool to manage insects associated with stored grain.

Acknowledgments We thank Bayer CropScience, especially Bill Striegel and Dennis Scott, for providing the insecticide formulations and partially funding this research. This paper is contribution number 11-325-J of the Kansas State University Agricultural Experiment Station.

Open Access This article is distributed under the terms of the Creative Commons Attribution Noncommercial License which permits any noncommercial use, distribution, and reproduction in any medium, provided the original author(s) and source are credited.

\section{References}

Abbott WS (1925) A method for computing the effectiveness of an insecticide. J Econ Entomol 18:265-267

Anonymous (2005) Spinosad; pesticide tolerance. Fed Regist 70:1349-1357

Arbogast RT (1991) Beetles: coleoptera. In: Gorham RJ (ed) Ecology and management of food industry pests. Association of Official Analytical Chemists, Arlington, pp 131-176

Athanassiou CG, Kavallieratos NG, Chintzoglou GJ, Peteinatos GG, Boukouvala MC, Petrou SS, Panoussakis EC (2008a) Effect of temperature and commodity on insecticidal efficacy of spinosad dust against Sitophilus oryzae (Coleoptera: Curculionidae) and Rhyzopertha dominica (Coleoptera: Bostrichidae). J Econ Entomol 101:976-981

Athanassiou CG, Kavallieratos NG, Yiatilis AE, Vayias BJ, Mavrotas CS, Tomanovic Z (2008b) Influence of temperature and humidity on the efficacy of spinosad against four stored-grain beetle species. J Insect Sci 8:1-9 
Athanassiou CG, Kavallieratos NG, Chintzoglou GJ (2008c) Effectiveness of spinosad dust against different European populations of the confused flour beetle, Tribolium confusum Jacquelin du Val. J Stored Prod Res 44:47-51

Athanassiou CG, Arthur FH, Throne JE (2009) Efficacy of spinosad in layer-treated wheat against five stored-product insect species. J Stored Prod Res 45:236-240

Athanassiou CG, Arthur FH, Throne JE (2010) Effects of short exposures to spinosad-treated wheat or maize on four storedgrain insects. J Econ Entomol 103:197-202

Athanassiou CG, Arthur FH, Kavallieratos NG, Throne JE (2011) Efficacy of spinosad and methoprene, applied alone or in combination, against six stored-product insect species. J Pest Sci 84:61-67

Bell $\mathrm{CH}$ (1976) Factors governing the induction of diapause in Ephestia elutella and Plodia interpunctella (Lepidoptera). Physiol Entomol 1:83-91

Bonjour EL, Phillips TW, Pitts JT (2006) Spinosad provides longterm protection for stored wheat. In: Lorini I, Bacaltchuk B, Beckel H, Deckers D, Sundfeld E, dos Santos JP, Baigi JD, Celaro JC, Feroni LRDA, de Bortolini OFL, Sartori MR, Elias MC, Guedes RNC, da Fonseca RG, Scussel VM (eds) Proceedings of the 9th international working conference for storedproduct protection. ABRAPOS, Canpinas, pp 1189-1193

Bret BL, Larson LL, Schoonover JR, Sparks TC, Thompson GD (1997) Biological properties of spinosad. Down Earth 52:6-13

Chintzoglou GJ, Athanassiou CG, Markoglou AN, Kavallieratos NG (2008a) Influence of commodity on the effect of spinosad dust against Rhyzopertha dominica (F.) (Coleoptera: Bostrichidae) and Sitophilus oryzae (L.) (Coleoptera: Curculionidae). Intl J Pest Manag 54:277-285

Chintzoglou GJ, Athanassiou CG, Arthur FH (2008b) Insecticidal effect of spinosad dust, in combination with diatomaceous earth against two stored-grain beetle species. J Stored Prod Res 44:347-353

Fang L, Subramanyam Bh, Arthur FH (2002) Effectiveness of spinosad on four classes of wheat against five stored-product insects. J Econ Entomol 95:640-650

Flinn PW, Subramanyam Bh, Arthur FH (2004) Comparison of aeration and spinosad for suppressing insects in stored wheat. J Econ Entomol 97:1465-1473

Getchell AI, Bh Subramanyam (2008) Immediate and delayed mortality of Rhyzopertha dominica (Coleoptera: Bostrichidae) and Sitophilus oryzae (Coleoptera: Curculionidae) adults exposed to spinosad-treated commodities. J Econ Entomol 101:1022-1027

Hertlein MB, Thompson GD, Subramanyam Bh, Athanassiou CG (2011) Spinosad: a new natural product for stored grain protection. J Stored Prod Res 47:131-146

Huang F, Subramanyam Bh (2007) Effectiveness of spinosad against seven major stored-grain insects on corn. Insect Sci 14:225-230

Huang F, Subramanyam Bh, Toews MD (2004) Susceptibility of laboratory and field strains of four stored-product insect species to spinosad. J Econ Entomol 97:2154-2159

Kavallieratos NG, Athanassiou CG, Vayias BJ, Kotzamanidis S, Synodis SD (2010) Efficacy and adherence ratio of diatomaceous earth and spinosad in three wheat varieties against three stored product insect pests. J Stored Prod Res 46:73-80

Mertz EP, Yao RC (1990) Saccharopholyspora spinosa sp nov isolated from soil collected in a sugar rum still. Int J Syst Bacteriol 40:34-39

Salgado VL (1998) Studies on the mode of action of spinosad: insect symptoms and physiological correlates. Pestic Biochem Physiol 60:91-102

SAS Institute (2005) SAS User's guide version 9.1.3, Cary, NC

Subramanyam Bh, Cutkomp LK (1987) Total lipid and fatty acid composition in male and female larvae of Indianmeal moth and almond moth (Lepidoptera: Pyralidae). Great Lakes Entomol 20:99-102

Subramanyam Bh, Hagstrum DW (1995) Resistance measurement and management. In: Subramanyam Bh, Hagstrum DW (eds) Integrated management of insects in stored products. Marcel Dekker, New York, pp 331-397

Subramanyam Bh, Toews MD, Ileleji KE, Maier DE, Thompson GD, Pitts TJ (2007) Evaluation of spinosad as a grain protectant on three Kansas farms. Crop Prot 26:1021-1030

Szabela DA (2005) The fate and efficacy of spinosad for insect management in farm stored corn. M.S. Thesis, Purdue University, West Lafeyette, pp 146

Thompson GD, Dutton R, Sparks TC (2000) Spinosad—a case study: an example from a natural products discovery programme. Pest Manag Sci 56:696-702

Toews MD, Subramanyam Bh (2003) Contribution of contact toxicity and wheat condition to mortality of stored-product insects exposed to spinosad. Pest Manag Sci 59:538-544

Toews MD, Subramanyam Bh, Rowan J (2003) Knockdown and mortality of eight stored-product beetles exposed to four surfaces treated with spinosad. J Econ Entomol 96:1967-1973

Vayias BJ, Kavallieratos NG, Athanassiou CG, Tatsi G (2010a) Insecticidal action of the combined use of spinosad and deltamethrin against three stored product pests in two stored hear-wheat varieties. In: Carvalho MO, Fields Alder CS, Arthur FH, Athanassiou CG, Campbell JF, Fleurat-Lessard F, Flinn PW, Hodges RJ, Isikber AA, Nvarro S, Noyes RT, Riudavets J, Sinha KK, Thorpe GR, Timlick BH, Trematerra P, White NDG (eds) Proceedings of the 10th international working conference on stored product protection, Estoril, Portugal, Julius Kühn Archiv Nr. 425, pp 921-924

Vayias BJ, Athanassiou CG, Milonas DN, Mavrotas C (2010b) Persistence and efficacy of spinosad on wheat, maize and barley grains against four major stored product pests. Crop Prot 29:496-505

Yousefnezhad-Irani R, Asghra PA (2007a) Susceptibility status of different life stages of Tribolium castaneum Herbst (Col: Tenebrionidae) to spinosad. Pak J Biol Sci 10:2950-2954

Yousefnezhad-Irani R, Asghra PA (2007b) Effect of spinosad on adults of Tribolium castaneum (Col: Tenebrionidae) and Sitophilus oryzae (Col: Curculionidae). Pak J Biol Sci 10:2505-2509

Zar JH (1984) Biostatistical analysis, 2nd edn. Prentice Hall, Englewood Cliffs 